\title{
PREVALENCE OF SPECIFIC LEARNING DISABILITIES AND ITS MANAGEMENT AMONG PUPILS IN CALABAR EDUCATIONAL ZONE, CROSS RIVER STATE
}

\author{
Orim Samuel Orim ${ }^{1 *}$, and Uko Francesca Uche Ezekiel ${ }^{2}$ \\ ${ }^{1}$ B.Ed, M.Ed (Special Education), Institute of Special Education, Palacky University \\ Olomouc,Czech Republic \\ Samuelorim1@gmail.com \\ ${ }^{2}$ B.Ed, M.Ed (Special Education), Institute of Special Education, Palacky University Olomouc, \\ Czech Republic \\ easyfavo@gmail.com \\ ${ }^{*}$ Corresponding author
}

\begin{abstract}
This study investigated the prevalence of specific learning disabilities and its management among pupils in Calabar educational zone, Cross River State. It adopted survey design,400 pupils between ages 6-14 years,200 teachers were purposively sampled across 20 schools were used for the study and three instruments two were designed by the researcher (learning disability checklist-LDC and teachers ability to manage learning disabilities-TAMLD), learning disabilities assessment and diagnostic Instrument -LDADI used in learning disabilities assessment center Jos, plateau state Nigeria. LDC and LDADI were used to identify specific learning disabilitieswhile TAMLD was used to assess teachers' ability to manage cases of learning disabilities in the classroom. All instruments were validated by experts in relevant fields. Data from thefield were analyzed using descriptive statistics. Findings indicated that there are eight sub types of specific learning disabilities are common among pupils in thesampled schools; these include dyslexia $26 \%$ $(n=104)$, dyscalculia 18\% ( $n=72)$, dysgraphia 16\% ( $n=64)$, ADHD 9\% $(n=36)$, dyspraxia $15 \%(n=60)$, dysorthgraphia3\% $(n=12)$, dyspinxia $8 \%(n=32)$, and dysmusia $5 \%(n=20)$. While $35 \%(n=70), 31 \%(n=62)$, of the teachers have poor and fair ability in managing specific learning disabilities others have $20 \%(n=40)$ and $14 \%(n=28)$ good and excellent ability to handle these disabilities. Based on the findings it was recommended among others that teachers' capacity should be built so that they professionally meet instructional needs of pupils with these disabilities if government policies like SDGs and Inclusion must be achieved in Nigeria.
\end{abstract}

Keywords: disabilities, prevalence, learning, children, instruction 


\section{INTRODUCTION}

From special educationperspective, exceptionality is a norm in human existence. The presence of persons with disabilities in any society makes itcomplete and worthy to be inhibited. The implication of this as popularized by theprinciples of equalityand Inclusion is that every society should be design to accommodate every member because the society expects members including those with disabilities to contribute to her development. This is why the Federal government of Nigeria made provision for contributions of PWDs in the National policy on Education(FGN 2008). The united Nations convention on rights of PWDs supports this position by expressly making provisions for education of these category of persons so that their potentials can be translated into positive contributions to self and their immediate society as well as the global community.

Persons with disabilities are those on the left hand side on the two divide of exceptionality. By definition these are persons who deviate from the normal pattern of growth and development accepted in any society, such deviations are direct results of the effect of impairment and must be significant to the extent that it requires specialized personnel, facilities, methods and adapted curriculum to be able to learn/engage in any other human activities in the society/school (Ozoji, 2005, Obi, 2006). These deviations implicate the role of parents, teachers and other stakeholders in the provision of essential services because such deviations affect their intelligence, physical growth/development, social interactions and emotional dispositions. Among PWDs, there are those who disabilities has no facial or sensory evidence yet it affect their ability to learn like every other child. This category according to APA(2013),Tanneck(2014) and International classification of Diseases $-10^{\text {th }}$ edition is called specific learning disabilities(SLD). Historically, the name was coined by Samuel kirk in the 60s. National Joint Committee on Learning Disabilities defines it as a general term that refers to a heterogeneous group of disorders manifested by significant difficulties in the acquisition and use of listening, speaking, reading, writing, reasoning, or mathematical abilities. These disorders are intrinsic to the individual and presumed to be due to central nervous system dysfunction. Problems in self regulatory behaviors, social perception and social interaction may exit with learning disabilities but do not by themselves constitute a learning disability. Even though a learning disability may occur concomitantly with other handicapping conditions (eg sensory impairment, mental retardation, social and emotional disturbance) or environmental influences (such as cultural differences, insufficient/ inappropriate instruction, psychogenic factors), it is not the direct result of those conditions or influences. Center for Learning Disabilities(2014) sees it as neurological disorders that impaired individual's ability to receive, store, process, retrieve information and communicate. Learning Disabilities Association of Canada (2012) defines SLD as a number of disorders which may affect the acquisition, organization, retention, understanding or use of verbal or non verbal information. These disorders affect learning in the individuals who otherwise demonstrate at least average abilities essential for human thinking and or reasoning. It result from impairment in one or more process related to perceiving, thinking, remembering or learning. These include but not limited to language processing, visual spatial processing, memory, attention and executive function such as planning and decision making.

From the above, it is obvious that this disability affects or limits one's ability to learn. To support this Bartonova (2014) notes that these disorders are directly related to skills acquired in school, and therefore almost inevitably lead to problems with mastering of reading, writing, or math's skills. The Salamanca declaration of 1994 advocate for Inclusive education/society with primary aim of building a society without any artificial barrier creating gap among members of the society on the basis of disability or ability. To enhance /support the policy of Inclusion and other such as EFA,MDGs and SDGs are initiated and implemented to increase access to quality education and build the capacity of every citizen including those with SLD so that they can be able to contribute positively to development of the society as well as earn a living.As result of marked success in the implementation of these policies the number of learners with disabilities particularly those with SLD in Nigeria have reasonably increased. Obani (2006) confirm that there is hardly any school or classroom in Nigeria that does that not have children with SLD. The population of this category is expected to continue to increase due to awareness. They constitute about half of the population of children with special needs in the school system. This trend has implications for government, parents and particularly teachers who drive the instructional process in the classroom to bring about the desired positive change(s) in behavior. The heterogeneity of SLD makes pedagogical responsibility of the teacher more complex because two children with this disability require different professional competency and experience. Researches such as Osuroji $(2010,2013)$ and the author experience indicate while the number of learners with this disability is high teachers that can manage their instruction needs in the classroom are grossly inadequate both in quality and in quantity. To manage children with SLD means, ability to meet or satisfy their instructional/learning needs in class. It entails teacher ability to maximizing the child area(s) of strength despite the presence of disability or deficit. It is equally teachers' ability to set instructional goals that reflect 
the child need and being able to successfully teach to the child's disability.

The concern of most professionals is that there are no specialists particularly in the field of SLD compared to the prevalence who can manage this category of learners in the school system. It is against this background that this study is design to find out the prevalence of SLD and whether teachers have the ability to meet their instructional needs in the classroom.

\section{PREVALENCE OF SPECIFIC LEARNING DISABILITIES IN SCHOOLS}

In special needs education practice prevalence is statistically the number of persons with disability in a given population. The incidence of cases leads to either low or high prevalence of each disability. The knowledge of prevalence of disabilities in the society is cardinal to effective planning and provision of services and may be proportionate to their enrollment in school. Available literature in special needs education generally indicates that SLDs has the highest number of disability cases. This is why it is often called high incidence disability. This fact is corroborated by the twenty six annual report of US congress (2005). The report notes that the category of SLDs far outnumbers the other categories with almost $50 \%$ of all children called exceptional children currently being identified as learning disabled.Altarac(2007) study indicates that the prevalence of SLD in US is $9.7 \%$. The study further reveals thatalthough cases of this disability is lower among average developing children(5.4\%), it still affect 2.7 million children compared with 3.3 million (27.8\%) children with special needs. As the number of those who meet the criteria increased from 1 to 5 , the prevalence of SLD increases from $15.0 \%$ to $27.1 \%, 41.6 \%, 69.3 \%$, and $87.8 \%$ respectively. Amanda(2010) reveals that Americans with SLD is 4.6 million. Heward (2000) findings shows that with passage of IDEA triple the number of students with SLD within the ages of 6-21 was 2.67 million in the 90 s to over 8.1 million. The author stated that this number does not include children who are in informal programmes in America. In a related study Peters(2010) estimate the prevalence of SLD among school children in USA at 2.9 million. They approximated that $5 \%$ of these children are in every public school. The author concludes that SLD is by far the largest category of children with special needs in America. Other studies by the same author indicate that the prevalence of SLD varies by with sex and age. It specifically shows that the number of boys with SLD outnumber the girls. The author noted that the high prevalence among male is due to their biological vulnerability. By age the author's findings show steady increase between age 6-9, decreases between age 10-13 and sharply decreases for individuals between 16-21 years of age.

Mogasale and Patial(2012)found out that in Indian the prevalence of dyslexia is 12.5\% for dysgraphia, $11.2 \%$ for dyscalculiaand $10.5 \%$ and $15.17 \%$ for other sub-types among the sampled children. They conclude that SLD in Indian is higher than other exceptionality and it is steadily increasing .For instant, 2012-2016 it rose from $8.10 \%$ to $15.1 \%$.Learning disabilities Association of Canada (2006) reports the prevalence of SLD after her participation in their PALS survey that $59.8 \%$ of children in the country have this disability, more than $3.2 \%$ of Canadian children in every school bus have SLD, $25 \%$ of children who transit form home to school need instructional accommodation to be able to cope with the disability and translate their potentials to achievement in school and more than half a million of adults have SLD and find university education /coping with different jobs very challenging. The study equally indicates that these disabilities among children have increased considerably between 2001 and 2016 particularly those within the age of 15-21 thus, making it the fastest growing disability in Canada.

The dearth of accurate data on prevalence of SLD is global concern however, in the Czech Republic bold steps and efforts have been made to solve the problem and this is yielding positive results.Bendova and Petrikova(2015) study indicates that $20 \%$ of children between the ages of 5-7 years in each school either are at risk or have SLD. The study also reveals that prevalence by gender is 1 girl to 3 boys, $60 \%$ of male and $40 \%$ of female have the disability.Bartonova (2014) studied 30 students with SLD in Bron city and discovered that $80 \%(n=24)$ are girls, $20 \%(n=6)$ are boys. The prevalence by sub type in the sample shows that $40 \%(n=12)$ have dyslexia, $7 \%(n=2)$ have dysgraphia, $7 \%(n=2)$ are dysorthographic, $7 \%(n=2)$ students have dyscalculia and $13 \%(n=4)$ of the students have dyslexia and dysgraphia while those with dysgraphia and dysorthographia is $26 \%(n=8)$. The author observed that girls have this disability than the boys and attribute it to the choice of secondary schools preferred by girls. Like in most schools/societies dyslexia is the largest among other subtypes as SLD is in other categories of exceptionality (Moody, 2007).

The challenge of getting realistic data on incidence of disabilities especially SLD is quite obvious in Nigeria due lack of operational definition, heterogeneity of the disability and identification/assessment criteria however, Obani(2006) estimate the prevalence to be 15-30\% while Telford and Sawrey in Osuroji(2013)put the prevalence among children within the school age to be $45 \%$, dyslexia alone has $25 \%$, attention deficit has about $15 \%$ and others has $5 \%$. Federal Ministry of Women affairs and Social Development (2011) in a baseline survey on PWDs report that SLD has the highest prevalence of about $58 \%$, reading disability takes about $31 \%$ leaving $11 \%$ to other sub-types. Department of Special Education University of Calabar(2015) 
screened 100 pupils in Calabar metropolis the result indicate that $25 \%$ has dyscalculia, $35 \%$ with dyslexia, $15 \%$ are dysgrahic, $10 \%$ has dyspraxia, attention deficit and others has $8 \%$ and $7 \%$.

A common feature in the review on prevalence of SLD in the countries mentioned is that this disability outnumber other categories of special needs. This trend has implications for specialist in the field and the government. Despite the variations in the figures onprevalence the present efforts are commendable because they give room for futureand constant research as well as form the basis for planning and provision for services especially for those in schools.

\section{MANAGEMENT OF SPECIFIC LEARNING DISABILITIES IN SCHOOLS}

It is a research based fact that SLD is a school/learning related disability; therefore its management is the primary concern /responsibility of the teacher. Management of specific learning disabilities among other meanings in simple terms is teachers' ability to meet instructional needs(skills to be learnt, areas of deficits, instructional goals) of the child with SLD in the classroom. It is equally the ability to control all instructional variables in the class to ensure that the child learns maximally. Teachers' ability to effectively do this depends on his/ her training and experiences, ability to do needs analysis of the child and align them with the instructional goals as well as other factors that enhance teaching-learning process. Like Johnson and Mykelbust in Obani(2006) pointed out, the problem of children with SLD is inability to translate their potentials into actual performance. This gap and the inability is the direct result of behavioral and learning characteristics manifested. This means that the primary task of the teacher is to find the how of tackling the difficulties and ensure that they learn optimally.

The comorbidity and heterogeneity of SLD makes it difficult to manage in class however, for lasting instructional/ therapeutic benefit instructions should be individually tailored to the finding of diagnostic evaluation and adapted to the student cognitive functional profile. To achieve this, theteachershould be ready to confront both intrinsic and extrinsic problems in the education of children with SLD. There are number of things the teacher/school must do to ensure that instructional needs of these learners are met. According to Lerner and Kline(2006) the responsibilities of teacher of student with SLD are difficult to defined and are changing rapidly. They are expected to identify,assess,collaborate,design and implement clinical or prescriptive instruction among others. In the same vain Osuorji (2013) study reveals that ability/ competence of SLD teacher can be categorized into competence in professional knowledge/skills and human relationship. The quality of instructional delivery and the ability to met instructional needs of these learners is directly proportional to his/her competence in these two areas. Robinson in Lerner and Kline(2006) find out in a study of teachers competence that ability to asses, adapt curriculum/pedagogical principles, manage learners behavior, manage learning environment, conduct objective instructional evaluation, choose and appropriately apply instructional accommodations as well as learning theories is cardinal to meeting instructional needs of children with SLD. Orim(2015) posits that any teacher who is poised to manage these disabilities should at all time be ready to ask and answer basic baseline questions such as, who should teach children with SLD?, what should he/she teach them?, why they should be educated? Where should they be taught?, how should they be taught? and when should they be taught? The who deals with the knowledge, training, personality, qualifications of the teacher? What to teach is concern with the curriculum as the source of instruction and other learning activities, why is the justification/rational for educating them despite the associated problems, where to teach them talks about placement alternatives/options, how to teach focus on the pedagogical principles, learning strategies and appropriate instructional accommodations .Lastly, the question on when gives directions to the early intervention to prevent secondary disability. Quality instructional that meets instructional needs of the learners dependson the teacher ability to practically, professionally and sincerely provide answers to the aforementioned issues.

Obani (2006) studied how pupils with LD in regular UBE schools are taught in Nigeria and summaries what teachers must do to include but not limited to the following:

- teach to the disability(needs of the child),

- teach clinical/prescriptively,

- teach the children to develop and use learning strategies/style appropriate to cognitive profile,

- apply current and research based instructional strategies,

- organize and use instructional resources creatively to enhance learning,

- build self esteem of the child,

- differentiate instructions for each child base on his/her strength, 
- teach to the child's level of tolerance.

Toister (2014) notes that, beyond teachers' ability to design instruction they need to develop capacity to work with others because the disability is heterogeneous. This confirms the philosophy in special needs education that no one professional/profession has the key to lock and open any disability. Among all disabilities this is very particular about SLD because it cut across varied areas, culture, ages, gender and field of study. In order to provide quality services to the clients all stakeholders especially teachers must build their human relation capacity. Key word in service delivery among PWDs is collaboration, as services for the clients' moves from one person to other the teacher needs to be able work with next service provider irrespective of his/ her profession, race, gender and other social pedigree. Collaboration requires the teacher to relate with parents to get first hand information on the experiences before, during and after pregnancy/birth and develop good rapport among other members of the child study team (CST). In a more critical dimension the teacher need to develop cordial and professional relationship with the child, look beyond his/her disability tothe personality of the learner and human dignity. In simple terms teacher must be able to work with others.

On the part of the school, it is incumbent on the authority to provide enabling and conducive learning environment, principally, the school should provide professional personnel in quantity/quality, cutting-edge facilities and motivate staff to boost their productivity. In the Czech Republic Bartonova(2014) reports that the government and schools through legislation provide opportunity for students with disability to graduate. The author specifically notes that that center for the reform of school -leaving examination (CERMAT) has been working with Czech Republic since 1999 and has reformed final examinations for students with SLD through graduation without a handicap policy.

\section{STATEMENT OF PROBLEM}

Learners with specific learning disabilities (SLD) like others have right to quality education and instruction in the classroom so that they can translate their potentials to asset for self and benefit of the society. This is the main thrust of school system in Nigeria especially in this era of inclusion and SDGs. Unfortunately, despite their potential and increased number in school/ classroom their instructional needs are not met like other peers without disability. This is because the disability is hidden, without sensory evidence and teachers lack professional ability to teach to their needs. This result to gross neglect, misconception and treatment. Some are call names that has negative psychological implications on their personality as learners and human beings as well as the learning process. Most importantly, schools lack the ability to protect their interest, needs and desire to learn this result to frustrations, development of disruptive behavior in class/school and eventual withdrawal from school. When this happens the same society see them as drop out and in an attempt to response to the unfair attitudes of the society/school they become a threat to peace and security .Thus, the statement of problem in this study in a question form is, what is the prevalence of SLD and teachers professional ability to meet the instructional needs of pupils with SLD in Calabar educational zone.

\subsection{Research Questions}

This study was guided by the following questions.

* What is the prevalence of specific learning disabilities in schools?

* What is the ability of teachers in managing specific learning disabilities in school?

\subsection{Methodology}

This study adopted survey design, 400 pupils between ages 6-14years,200 teachers with or without special education background were purposively sampled across 20 primary schools in the educational zone were involved in the study. Three instruments were used for the study, learning disabilities checklist was used to screen 520 pupils, and 120 of them that did not meet the criteria for actual diagnosis were dropped and were not part of the sample. Learning disabilities checklist (LDCL) had 20 items that covers characteristics often manifested by those with the disability, learning disabilities assessment and diagnostic instrument (LDADI) used 28 items in Learning Disabilities Assessment Center Jos, Plateau state covers figure ground, form constancy, spatial relationship, position in space, concentration on task, copying of written samples and eyehand coordination. Teacher rating instrument was made up of 30 items assess teachers in areas like methodology, evaluation of students performance, instructional differentiation, presentation, knowledge of accommodations and collaboration with other professionals. All the instruments were validated by professionals in the field and educational measurement/research. Teachers rating instrument was used to assess their ability to manage cases of SLD in class while others were used to assess and identify children with SLD in sampled schools. A team of three professionals in SLD assisted the researcher in screening and identification of children as well as in assessment of teachers' ability in managing case of learning 
disabilities. Consent of parents was gotten through the efforts of PTA of the schools, written approval from Ministry of Education and letter of introduction from researcher was presented the authority of sampled schools. Children consent was also gotten and they had right to withdraw from the study for reason(s) and professional best practices in assessment process were upheld and confidentiality of data about clients was not compromised. Descriptive statistics were used to analyze data from the field.

\subsection{Presentation of Result}

Research question 1. What is the prevalence of specific learning disabilities in schools?

Table 1 shows the prevalence of the disabilities is the samples schools

\begin{tabular}{lll}
\hline Disability & Areas of difficulty & Prevalence \\
\hline Dyslexia & Reading & $26 \%$ \\
\hline Dyscalculia & Number/maths & $18 \%$ \\
\hline Dysgraphia & Handwriting & $16 \%$ \\
\hline ADHD & Concentration on tasks & $9 \%$ \\
\hline Dyspraxia & Motor skills & $15 \%$ \\
\hline Dysorthgraphia & Grammar/sentence formation & $3 \%$ \\
\hline Dyspinxia & Drawing & $8 \%$ \\
\hline Dysmusia & Singing/music & $5 \%$
\end{tabular}

PREVALENCE OF SPECIFIC LEARNING DISABILITIES IN SCHOOLS

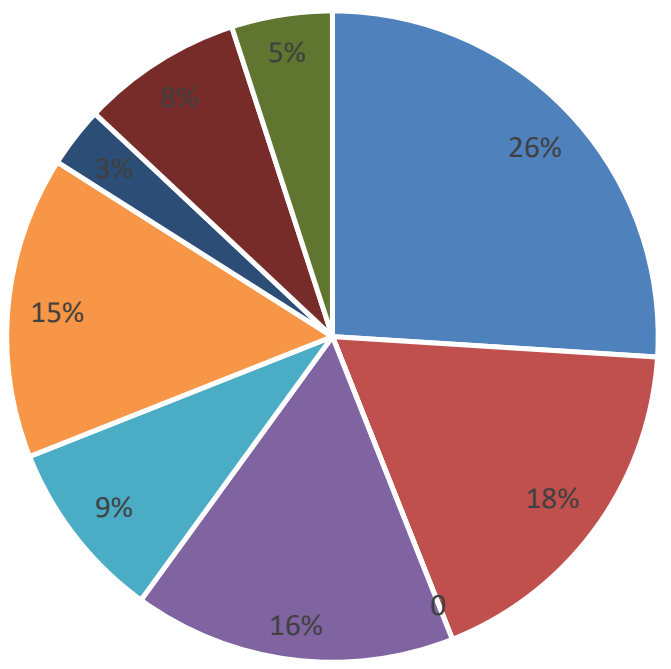

$$
\begin{array}{lll}
- \text { Dyslexia } & \text { Dyscalculia } & \text { Dysgraphia } \quad \text { ADHD } \\
\square \text { Dyspraxia } \quad \text { - Dysorthgraphia } \square \text { Dyspinxia } \quad \text { Dysmusia }
\end{array}
$$

Figure 1 pie chart showing the prevalence of specific learning disabilities in schools. 


\section{Prevalence of Specific Learning Disabilities in Schools}

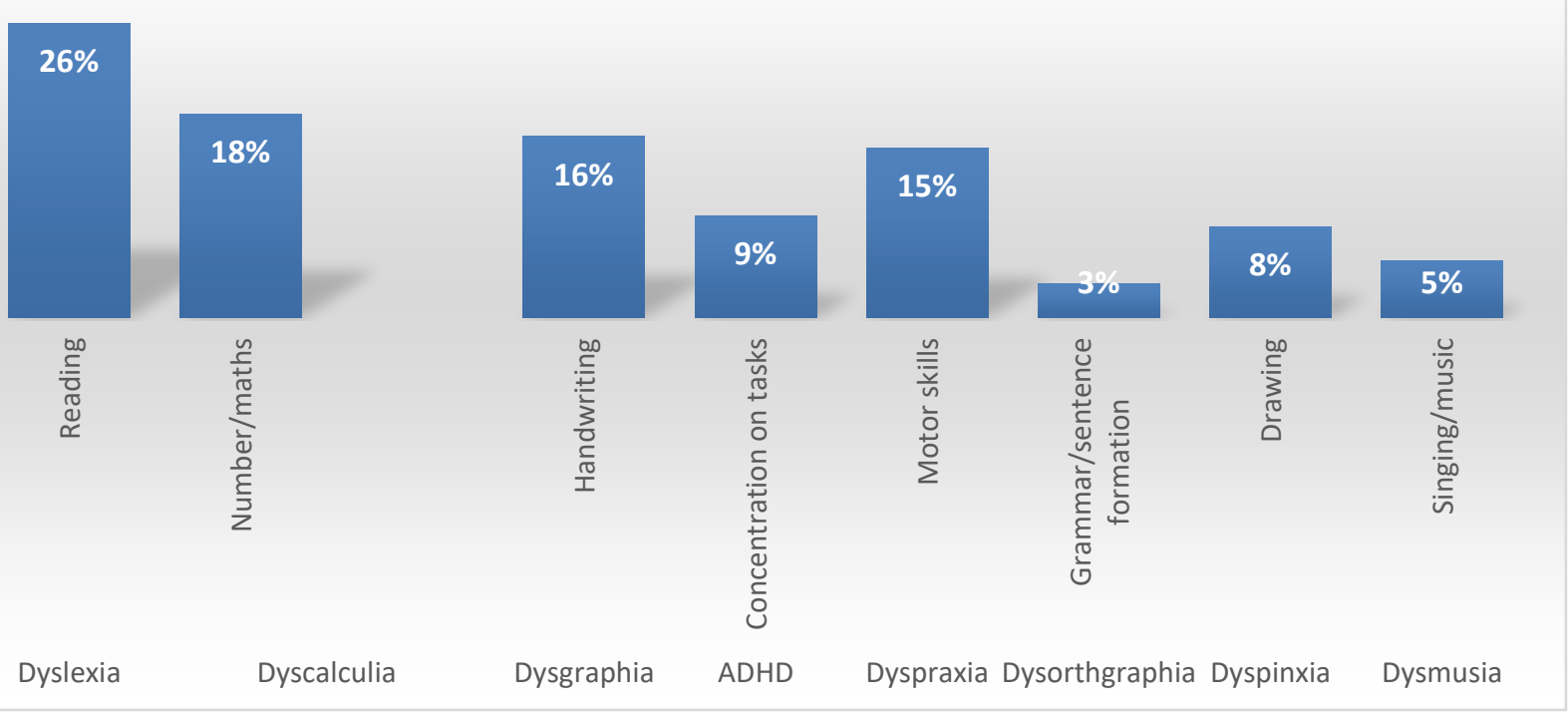

Figure 2 bar chart indicating the prevalence of the disability in school

Result in table 1, figure 1 and 2 above shows the prevalence of specific learning disabilities among pupils in Calabar educational zone. It indicates that pupils have these disabilities in the schools. Specifically,26\% have reading disorders, $18 \%, 16 \%$ and $9 \%$ of them have number/mathematics ,handwriting and attention disorders. While $15 \%, 3 \%, 8 \%$, and $5 \%$ have disability that affect their ability to use motor skills, make simple /correct sentences, draw and perform well in varied aspects of music. These findings also reveals that a child has more than one disabilities confirming the concomitancy of SLD as seen in National Joint Committee on Learning Disabilities conceptual frame work of the disability.

Research question 2 what is teachers' ability in managing specific learning disabilities in schools?

\section{Teachers Ability in Managing Pupils with Disabilities}

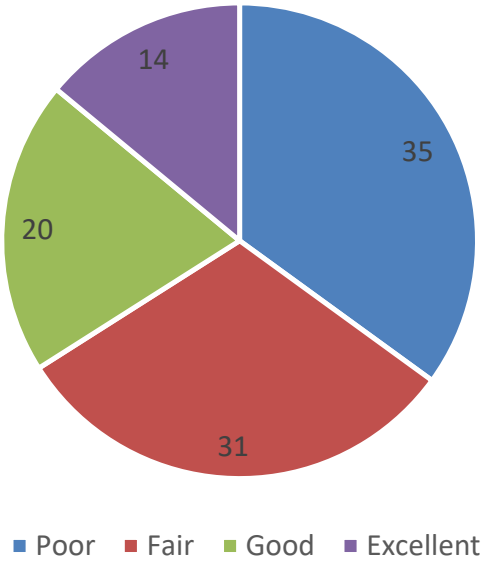

Figure 3 pie chart showing teachers ability in managing specific learning disabilities in school. 


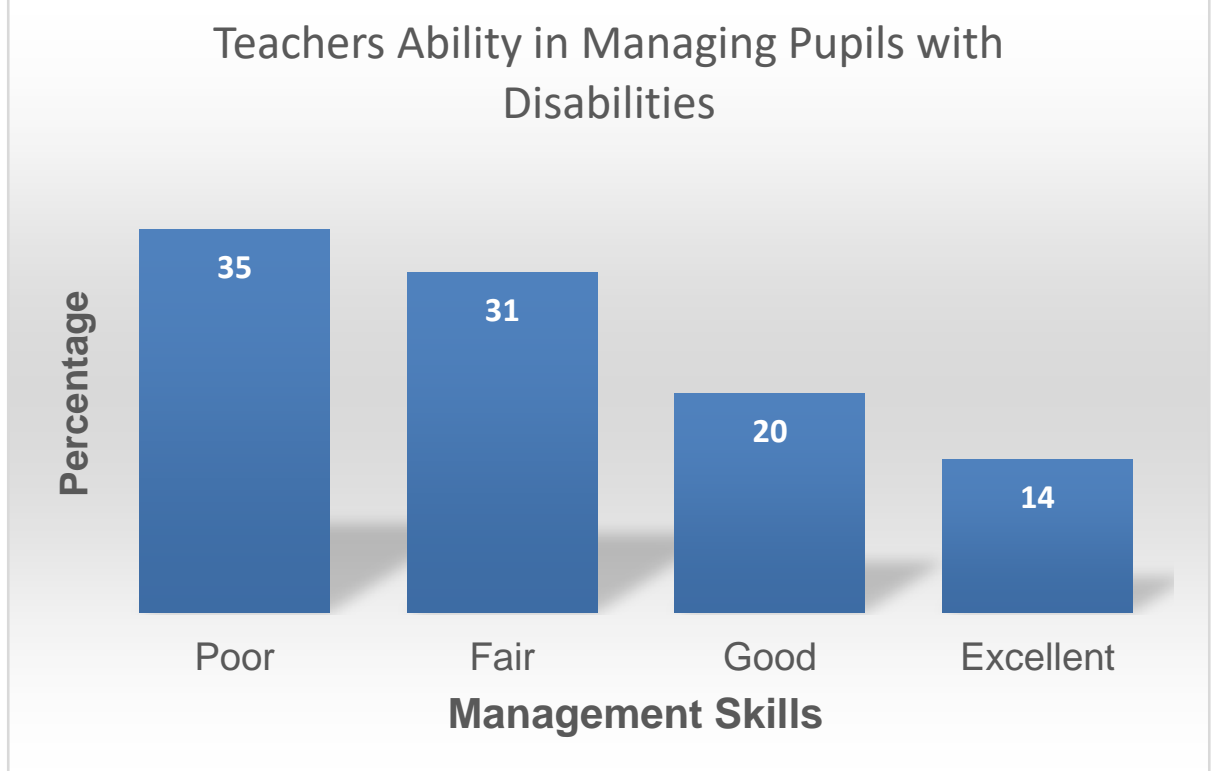

Figure 4 bar chart presents teacher ability in handing cases of specific learning disabilities in schools.

Result in figure 4 above indicates that 35\% ( $n=70), 31 \%$, $(n=62), 20 \%(n=40)$ and $14 \%(n=28)$ of teachers have poor, fair, good and excellent ability in meeting instructional needs of children with the disability in the classroom.

\subsection{Discussion of Results}

This study was guided by two research questions. Findings for research question one seeks to know the prevalence of specific learning disabilities in schools as shown in table 1 indicate that eight sub-types of the disabilities are common among pupils in schools and dyslexia outnumbered others. The findings of this study are supported by Kelechi and Olabisi(2012). They report that specific learning disabilities have the highest number of cases among children with special needs in Nigerian schools. Their study further shows that reading disabilities is frequently diagnosed in children. This present study is equally validated by the Hassana(2012) who study reveals that the ratio of SLD to others disabilities is $3: 1$ in primary schools. In a contrast, Mayern (2015) reports that SLD is/will remain victim of over diagnosis among diagnosticians due the generic nature of the disability. The author argues that high rate of the disability is a function of the use of faulty criteria for identification. She notes that until all issues in assessment and diagnosis of specific learning disabilities are professionally addressed it will still be over represented.It is instructive for professionals and other stakeholders to give adequate attention to alarming figures associated with this disability because the trend is universal concern which is an indication that the disability needs more proactive global efforts.

The result for research question two that deals with teachers ability to manage SLD in the classroom reveals that majority of teachers in schools have very poor ability to manage cases of learning disabilities .This findings agrees with Anne(2016) who reports that most teachers lack professional competence to manage instructional needs of learners with this disability. Moshe (2013) equally corroborate these findings in a study that shows teachers inability meet instructional needs of pupils with reading disorders because they professionally ill equipped. The researcher believes that this is principally why most children are either vulnerable or have the disability. Obani (2006) reports that in regular UBE in Nigeria most teachers have teaching disability due to lack basic knowledge on pedagogical principles. He found out that $78 \%$ of teachers cannot adapt instructional strategy to suit the learning profile of child with this special need. They are also unable to teach to child level of tolerance, individualized learning activities, apply instructional accommodations and other essential rudiments in teaching learners with this disability.

This trend is both immediate and long term effect on the children and the society. They are excluded from teaching - learning process in class and there is a likely hood policy like Inclusion and SDGs will not be achieved. Like Danny(2016) notes, when the school system / society fails to adequately meet needs of learners at the appropriate time they will wait for the society and she will live remember the negative effect of this on posterity. 


\section{CONCLUSION}

It is a research fact that disability and the society are cannot exist in isolation therefore hence they need each other at different time is important the society through its system like the school should brace up the challenges of having PWDs in the society/school. This requires prompt and pragmatic steps because those with disabilities especially SLD have the consciousness that education is their right and they policies/legislative backing. This is responsible for the steady increase in the number of this category in school without meeting their instructional needs. Base on this study it is educative that all stakeholders in Nigeria should adequately plan for quality education of these citizens through:

1. Funding of researches in the field to provide first hand information or data needed for effective planning and implementation,

2. Professionals should produce globally relevant compass for assessment and identification of SLD with due regards to national issues or peculiarity,

3. Teachers capacity building should be specifically design to meet the increasing need for teacher with competence in educating children with this disability,

4. Workable collaborative framework should be initiated to ease the challenges of educating children with this disability in Nigeria.

\section{REFERENCE LIST}

Altarac, M.(2007).Life time prevalence of learning disability among children. Retrieved from www.ncbi.nlm.nih.gov/pubmed/17272589

Anne,V.E.(2016).Managing learning disabilities in Inclusive classrooms. Journal of Inclusive Education, 1 (3), 40-48.

Amanda,M.(2010). Learning disabilities facts, trends and statistics. Retrieved from understood.org/en/learning-attention-Issues/getting started/what- you-need-to-know/learningdisabilities-fact-trends and stats

American Psychiatric Association, APA (2013).Diagnostic statistical manual. Author

Bartonova, M.(2014).Approaches to students with learning disorders in Inclusiveschool environment. Masaryk University: Muni press.

Bendova,P.\& Petrikova,M.(2015).The risk of developing specific learning difficulties in children aged 5.5-7 years in the Czech Republic. Retrieved from www.library.tated.org.

Center for Learning Disabilities (2014). The state of learning disabilities $3^{\text {rd }}$ edition. Author.

Danny, C.B.(2016).Failure of the school system: Implications for posterity. Journal of Disability and the Society,3(6)81-92

Department of Special Education, University of Calabar (2015).Assessment andldentification of pupils with disabilities in schools. Author.

Federal Government of Nigeria(2008). National policy on education withstrategic Implementation plan. Lagos: NERDC

Federal ministry of Women affairs and Social Development (2011). Baselinesurvey on persons with disabilities. Author.

Hassan,S.D.(2012). Assisting children with learning disabilities to cope with Inclusion through diet modification and supplement. African Journal of InclusiveEducation, 1(1),39-43.

Heward, W.L (2000). Exceptional children: An introduction to special education $6^{\text {th }}$ edition. New Jersey: Prentice Hall.

Kelechi, U.L. \& Olabisi,I. A.(2012).Basics of inclusive education for children in Nigeria. African Journal of Inclusive Education 1,(1),18-29. 
IJAEDU- International E-Journal of Advances in Education, Vol. III, Issue 9, December 2017

Learning Disabilities Association of America (2006). Dysgraphia. Retrieved from www.idamerica.org/aboutld/parent/ld-basic/dysgrphia.asp.

Learning Disabilities Association of Canada(2012). Prevalence of learning disability. Retrieved from www.ldac-act.ca/learn-more/ld-basics/prevalence-of Ids.

Lerner, W.J.\& Kline, F.(2006). Learning disabilities and related disorders, Characteristics, and learning strategies. USA: Houghton Mifflin Company.

Moody, S.(2007). Dyslexia: surviving and succeeding at college. New York: Routlege Taylor Francis Group.

Mayern, V.I.(2015).Issues in assessment and Identification of specific learning disabilities

Moshe,A.(2013).Teaching reading strategies: mediation for transcendence as tool for students acquisition and internalization. In L.Prochachzkova \& P.Sochor(eds). Support of people with special needs: international perspectives. Masaryk University: Muni Press

Mogasale, V.V,\& Patil,V.D.(2012).Prevalence of specific learning disabilities among children in South Indian City. Retrieved from www.ncbi.nlm.nih.gov/pubmed/21887581.

Ozoji, E.D(2005).Special education and rehabilitation for beginnerprofessionals. Jos: Deka publication.

Obi, F.B.(2006). Essentials of special educational needs. Calabar: Klentin Educational Publishing.

Obani,T.C.(2006).Teaching the learning disabled in the regular UBE schools and classrooms. In T.C. Obani (ed). Teaching pupils with special needs in regular UBE classroom .Ibadan: Olubem prinrers.

Orim,S O.(2015).Teaching or cheating learners with learning disabilities in school. Course materials on EDS 222, education of children with learning disabilities, Department of special education, University of Calabar.

Osuorji P.I.(2010).understanding learning disabilities from assessment and diagnosis perspectives: A clinical experience for specialist. The ExceptionalChild, 12 (1), 106-116.

Osuorji,P.I(2013). Assessment needs on learning disabilities for inclusive education in Nigeria. The Exceptional Child, 15(1), 133-142.

Peters,H.K(2010).Prevalence of specific learning disabilities among school children in America. Journal of Exceptionality, 1(1),34-45.

Toister,J.(2014).Instructional design essentials: needs analysis. Retrieved from www.lynda.com/highereducation-tutorials/instructional-design-essentials-needs-analysis/170069-2.

Tanneck,R.(2014).DSM-5changes in diagnostics criteria for specific learning disabilities: what are the implications. International Dyslexia Association. Author

US Congress (2005).Twenty-six US report on persons with disabilities. Author. 